\title{
Bemerkungen und Versuche betreffs der Resorption in der Bauchhöhle.
}

Von

\section{R. Heidenhain.}

Im neunundfünfzigsten Bande dieses Archivs hat Dr. W. N. O rlow die Ergebnisse einer in meinem Institut angestellten Untersuchung über die Resorption in der Bauchböhle mitgetheilt. Sie lauteten dahin:

1) Die wesentliche ${ }^{1}$ ) Function bei der Anfsaugung in der Unterleibshöhle haben nicht die Lymphbahnen, sondern die Blutbahnen.

2) Eine Reihe von Thatsachen, die bei der Resorption beobachtet werden, lässt sich auf einfachen Diffussionsaustausch zwischen Blut und Bauchhöhleninhalt zurückführen.

3) Neben den durch Osmose deutbaren Erscheinungen treten bei der Aufsaugung gewisse andere auf, für welche jener physikalische Process nicht verantwortlich gemacht werden kann. Sie

1) Vgl. Orlow's Aufsatz S. 179. Ich lasse das Wort "wesentlich" hier gesperrt drucken; denn der Leser einer gleich zu besprechenden $A b$ handlung von W. Cohnstein könnte, wenn er dessen Referat nicht mit dem Wortlaute der $0 \mathrm{rl}$ ow'schen Arbeit vergleicht, den Eindruck gewinnen, als hätte letzterer die a uss chliessliche Function der Blutcapillaren behauptet. Davon ist aber bei 0 rlow nirgends die Rede und konnte es auch gar nicht sein. Jeder Physiologe kennt wohl aus eigner Anschauung die durch Recklinghausen sichergestellte Thatsache, dass in die Lymphwege des Zwerchfelles an seinem sehnigen Theile Flüssigkeiten und in ihnen suspendirte körperliche Elemente mit Leichtigkeit eindringen. Diese Thatsache zu bestreiten ist Orlow nicht in den Sinn gelrommen. Sie sagt doch aber gar Nichts darüber aus, wi e gross der Antheil der Lymphwege an der Flüssigkeitsresorption sei. Orlow behauptet nur, dass den wesentlichen, d. h. ganz überwiegenden Antheil die Blutwege haben. 
deuten auf Triebkräfte hin, welche in den Wandungen der Bauchböhle ihren Ursprung nehmen.

Gegen diese Schlussfolgerungen, welche Orlow aus seinen Beobachtungen gezogen hat, ist kürzlich W. Cohnstein aufgetreten $^{1}$ ). Er behauptet, dass da, wo die Osmose zur Deutung der Resorption nicht ausreiche (bei Aufsaugung isotonischer Flüssigkeiten), die Aufsaugung durch die Lymphbahnen vermittelt werde.

Der Aufsatz Cohnstein's zwingt mich zunächst zu einigen allgemeinen Bemerkungen, welche für die Besprechung seiner Anschauungen und seiner Versuche nicht umgangen werden können. Denn seine Ansichten über Osmose, osmotische Spannung u. s. f. weichen in mancher Beziehung von den Grundsätzen der heutigen Diffusionslehre $a b$, ohne dass er diese Abweichung theoretisch oder experimentell begründet hätte. Der Vorgang der Osmose ist ja heute, dank den Fortschritten der physikalischen Chemie, viel durchsichtiger geworden, als er es vor 20 Jahren war. Als ich meine Beobachtungen über Resorption im Dünndarm veröffentlichte ${ }^{2}$ ), versuchte ich die für die Physiologie wichtigen Grundvorstellungen der Osmoselehre in einige kurze, der heutigen Ausdrucksweise angepasste, Sätze zusammenzufassen. Von den bei jener Gelegenheit von mir betonten Lehren der Physik entfernen sich Cohnstein's Anschauungen in bemerkenswerther Weise.

Der zweite der damals von mir hervorgehobenen Sätze lautet: „Befinden sich auf den beiden Seiten einer Diffusionsmembran wässerige Lösungen von ungleicher endosmotischer Spannung, so geht Wasser von der Seite der geringeren Spannung nach der anderen Seite über". Cohnstein aber hält es (auf der vierten Seite seines Aufsatzes) für „bewiesen, dass differente Flüssigkeiten (Farbstofflösungen, hyp- oder hy peris oton is che Salzlösungen) durch die Capillaren des Peritoneums ebenso gut wie durch die Capillaren anderer Organe resorbirt werden können; die hierbei wirksame Kraft ist die Osmose".

lch branche wohl kein Wort darüber zu verlieren, dass das, was ich habe gespert drucken lassen, nämlich die Resorption hyperisotonischer Lösungen durch die Blatcapillaren vermit telst der Osmose, nicht in Uebereinstimmung mit den Grund-

1) W. Cohnstein, Centralbl. f. Physiologie vom 21. September 1895.

2) Dieses Archiv Bd. 56, S. 579, 1894. 
sätzen der Physik steht. Zu jener Lösung muss Wasser aus den Capillaren übertreten, aber nicht umgekehrt, wenn es sich nur um Osmose bandelt.

Weiter habe ich a. a. O. hervorgehoben: „Die endosmotische Spannung eines Lösungsgemenges ist gleich der Summe der Partiarspannungen der einzelnen gelösten Bestandtheile". Cohnste in identificirt nun in seinem Aufsatze durchgehends die Partiarspannung eines Lösungsbestandtheiles und die Gesammtspannung der Lösung. Nur so ist es erklärlich, dass er eine 0,6\% Kochsalzlösung für isotonisch mit der Blutflüssigkeit hält. In der letzteren einen Kochsalzgehalt von 0,6\% vorausgesetzt, was etwas zu niedrig ist - hat das Kochsalz eine Partiarspannung, welche der Spannung desselben in der sogenannten physiologischen Kochsalzlösung entspricht. Aber die Gesammtspannung der Blutflüssigkeit geht, dank der Anwesenheit vieler anderer Lösungsbestandtheile, beträchtlich uiber die Spannung jener Salzlösung $(0,6 \%)$ hinaus; sie entspricht bei Hunden nahezu einer einprocentigen Kochsalzlösung. Die „physiologische“ Kochsalzlösung von $0,6 \%$ ist also nicht mit der Blutflüssigkeit isotonisch (obschon es die Kochsalzspannung in beiden Flïssigikeiten ist), sondern sehr erheblich hypisotonisch.

Die eben hervorgehobene Verwechslung zwischen Partiarspannung und Gesammtspannung zieht sich durch die ganze Arbeit Cohnstein's und hat für seine Versuche eine verhängnissvolle Bedeutung gewonnen.

Cohnstein's Zweek ist nun zu beweisen, dass bei der Resorption isotonischer Salzlösungen die Lymphbahnen die Vermittlung übernehmen, während Orlow für die Blutbahnen eingetreten war. Letzterer kam zu seiner Auffassung durch die einfache Beobachtung, dass bei der Resorption erheblicher Mengen von isotonischen Flüssigkeiten (Serum, einprocentige Kochsalzlösung) der Lymphstrom im Duct. thoracieus nicht ansehwillt.

Cohnstein's experimentelle Gegengrinde wollen einzeln besprochen sein.

\section{Erster Beweis Cohnstein's.}

„Wenn die Blutcapillaren die Resorption intraperitoneal in fundirter isotonischer Kochsalzlösung vermittelten, so müsste eine allmähliche Verdünnung des Blutes zu constatiren sein. Dies ist niemals der Fall". Als Beweis wird ein Versuch angefiuhrt.

Hierauf habe ich vielerlei zu erwidern: 
Bemerkungen und Versuche betreffs der Resorption in der Bauchhöhlə. 323

1) Cobnstein's Beweis ist schon deshalb vollständig missglïckt, weil er nicht eine wirklich isotonische (1\%), sondern eine vermeintlich isotonische, in Wirklichkeit bypisotonische $(0,6 \%)$ Kochsalzlösung (und zwar in der enormen Menge von 2 Litern) in die Bauchhöhle infundirte. Er hält es aber für bewiesen, dass „hypisotonische Lösungen durch die Capillaren des Peritoneums resorbirt werden können". Und trotzdem keine Verdünnung des Blutes? Da muss es wohl mit jenem Criterium, welches zwischen Blut- und Lymphbahnen entscheiden soll, nicht ganz sicher bestellt sein.

2) In Wirklichkeit verdünnt sich das Blut sowohl bei Resorption 0,6 procentiger, als einprocentiger Kochsalzlösung, aber nur in geringem Maasse. Cohnste in ist diese geringgradige Verdünnung wahrscheinlich deshalb entgangen, weil er den Wassergehalt des Gesammtblutes bestimmte. Dieser ist aber in hohem Grade abhängig von dem bekanntlich leicht wechselnden Verbältniss zwischen Plasma und Körperchen. Zudem erfordert die Bestimmung des Wassergehaltes des Gesammtblutes ganz besondere Vorsicht, weil dasselbe beim Trocknen die letzten geringen Antheile von Wasser sehr lange zurïckhält. Doch will ich durchaus nicht annehmen, dass Cohnstein jene Vorsicht nicht angewandt habe. Sicherer ist jedenfalls schon aus dem zuerst angeführten Grunde die Bestimmung des Wassergehaltes des Serums; dieser wächst während der Resorption, wie schon oben bemerkt, nach Ausweis folgender Bestimmungen:

I. Hund ${ }^{1}$ ) von 5,5 Kilo. Lymphe durch eine Canäle aus dem D. thoracicus nach aussen geleitet. $\mathrm{Um} 10 \mathrm{~h}$ Infusion von $125 \mathrm{ccm}$ Kocbsalzlösung von $0,63 \%$ in die Bauchhöhle. - Trockengehalt des Blutserums:

$$
\begin{aligned}
& 10 \mathrm{~h} 15^{\circ} \text {. . . 7,99\% } \\
& 31^{\prime} \cdot \text {. } 7,81, \\
& 11 \mathrm{~h} 31^{\prime} \text {. . } 7,60 \text {, } \\
& 12 \mathrm{~h} 37^{\circ} \text {. . . 7,54" }
\end{aligned}
$$

\begin{tabular}{|c|c|c|}
\hline Oh $6^{\prime}$ & & 8,1 \\
\hline $52^{\prime}$ & . & 7,5 \\
\hline I1h $6^{\prime}$ & . & 7,41 \\
\hline h $6^{\prime}$ & & 7,14 \\
\hline $1 \mathrm{~h} 6^{\prime}$ & & \\
\hline
\end{tabular}

II. Hund ${ }^{1}$ ) von 7,5 Kilo. Derselbe Versuch. 9h 52'-56,5' Infusion von $244 \mathrm{ccm}$ einprocentiger Kochsalzlösung. Trockenrückstand des Serum :

1) Seit 48 St. nüchtern. 
Da bei diesen beiden Versuchen eine Reihe von Blutproben von je $20 \mathrm{ccm}$ entnommen waren, könnte eingewendet werden, die Verdünnung des Serum sei Folge der Blutentziehung. Bei dem folgenden Versuche wurden deshalb nur 3 Bestimmungen gemacht.

III. Hund ${ }^{1}$ ) von 7,5 Kilo. Infusion von $240 \mathrm{~cm} 1$ procentiger Kochsalzlösung (von $9 \mathrm{~h} 52-56^{1} / 2^{\prime}$ ). Trockenrückstand des Serum

$$
\begin{aligned}
& \text { um } 9 \mathrm{~h} 51^{\prime} \text {. . . 7,46\% } \\
& \text { 11h } 32^{\prime} \text {. . . 7,27, } \\
& 1 \mathrm{~h} \quad \text {. . } 7,21,
\end{aligned}
$$

Eine Verdünnung findet also in allen Versuchen statt, aber sie ist allerdings sehr geringfügig.

3) Cohnstein hat seinen Versuchsplan nicht durch die erforderlichen Controllversuche gerechfertigt. Ich meine Folgendes.

Die Resorption von $0,6 \%$ oder $1 \%$ Kochsalzlösung erfolgt sehr langsam. Wie viel in Cohnstein's Versuchen resorbirt worden ist, hat er anzugeben versäumt. In meinen Versucben wurden resorbirt:

in $I$ während rund $21 / 2$ Std. pro $1 \mathrm{~kg}$ Körpergewicht $10 \mathrm{ccm}$ (im Ganzen $55 \mathrm{ccm}$ bei $5,5 \mathrm{~kg}$ Körpergewicht).

in II während rund 3 Std. pro $1 \mathrm{~kg}$ Körpergewicht $14 \mathrm{ccm}$ (im Ganzen $104 \mathrm{ccm}$ bei $7,5 \mathrm{~kg}$ Körpergewicht).

in III während rund 3 Std. pro $1 \mathrm{~kg}$ Körpergewicht $10,6 \mathrm{ccm}$ (im Ganzen $80 \mathrm{ccm}$ bei $7,5 \mathrm{~kg}$ Körpergewicht).

Es fragt sich doch nun vor Allem, ob bei intravenöser Einführung von $10-14 \mathrm{cem}$ Kochsalzlösung $(0,6-1,0 \%)$ pro Kilo innerhalb $21 / 2-3$ Stunden der Wassergehalt des Blutes wesentlich mehr steigt, als wenn jene Menge bei der Resorption aus der Bauchböhle verschwindet. Das ist nicht der Fall, wie folgende Zahlen zeigen.

IV. Hund von 11 Kilo. Trockengehalt des Serums um $9 \mathrm{~h} 3 \mathrm{l}^{\prime}$ gleich $6,85 \%$. Von $9 \mathrm{~h} 32^{\prime}$ bis $12 \mathrm{~h} 30^{\prime}$ fliessen in die Vena facialis gleichmässig 106,8 ccm einprocentiger Kochsalzlösung (jede Minute 0,6 ccm). Der Trockengehalt des Serums betrug

$$
\begin{aligned}
& \text { um } 11 \mathrm{~h} \text {. . 6,72\% } \\
& 12 \mathrm{~h} 31^{\prime} \text {. . . 6,48, }
\end{aligned}
$$

V. Hund von 10 Kilo. Trockengehalt des Serum

$$
9 \mathrm{~h} 35^{\prime} \text {. . . 8,01\%. }
$$

Von $9 \mathrm{~h} 37,5^{\prime}$ bis $11 \mathrm{~h} 50^{\prime}$ fliessen in die Vene langsam und möglichst gleichmässig $100 \mathrm{ccm} 1$ procent. ClNa-Lösung. Um $11 \mathrm{~h} 50^{\prime}$ beträgt der Trockengehalt $7,49 \%$.

1) Seit 48 St. nüchtern. 
Bemerkungen und Versuche betreffs der Resorption in der Bauchhöhle. 325

Wir baben also:

a) Resorption.

Troekengehalt des Serum am Anfange am Ende

\begin{tabular}{|c|c|c|c|c|c|}
\hline No. Dauer & Meng & pro Kilo & der Resor & onszeit & Differen \\
\hline $2 \mathrm{~h} 37^{\prime}$ & $10 \mathrm{ccm}$ & $\mathrm{ClNa} \quad 0,6 \%$ & $\left.7,99 \% 0^{1}\right)$ & $7,54 \%$ & $0,45 \%$ \\
\hline $3 \mathrm{~h}$ & 14 & $\Rightarrow 1 "$ & $8,15,, 2)$ & 7,12, & 1,03, \\
\hline $3 \mathrm{~h}$ & 10,6, & $1 "$ & $\left.7,46,{ }^{3}\right)$ & 7,21, & 0,25 \\
\hline
\end{tabular}

b) Intravenöse Infusion.

Trockengehalt des Serum am Anfange am Ende

No. Dauer Menge pro Kilo der Infusion Differenz

IV $32^{\prime} \quad 9,7 \mathrm{ccm}$ ClNa $\left.1 \quad \% \quad 6,72 \%{ }^{4}\right) \quad 6,48 \% \quad 0,24 \%$ $\left.\mathrm{V} \quad 2 \mathrm{~b} 12^{1} \mathrm{~g}^{\prime} \quad 10 \quad, \quad, \quad 1, \quad 8,01,{ }^{4}\right) \quad 7,49, \quad 0,52$,

Werden also in gleicher Zeit gleiche Flüssigkeitsmengen aus der Bauchhöhle resorbirt oder unmittelbar in das Blut infundirt, so ändert sich der Wassergehalt des Blutserums in beiden Fällen in ganz ähnlichen, sehr engen Grenzen. Der dem Blute auf dem einen oder anderen Wege zugeführte Wasserüberschuss wird fast vollständig aus dem Blute wieder entfernt.

Aus den obigen Ergebnissen folgt, dass der erste Beweis, welchen Cohnstein für die Resorption isotonischer Kochsalzlösungen durch die Lymphbahnen geltend macht, nicht stichhaltig ist.

\section{Zweiter Beweis Cohnstein's.}

„Unter der gleichen Voraussetzung (d. h. wenn die Blutcapillaren die Resorption vermittelten) müsste eine Zunahme der Harnsecretion zu beobachten sein. Dies ist nicht der Fall".

Ich kann nur hinzufügen, dass die intravenöse Einfuihrung (wirklich) isotonischer Kochsalzlösung, wenn sie so langsam geschieht, wie die Resorption erfolgt; ebenfalls keine wesentliche Steigerung der Harnsecretion herbeiführt. Messende Versuche iber die Harnsecretion scheint Cohnstein nicht angestellt zu haben.

1) $15^{\prime}$ nach der Infusion in die Bauchhöhle.

2) $10^{\prime}$ nach der Infusion in die Bauchhöhle.

3) Unmittelbar vor der Infusion.

4) Unmittelbar vor der Infusion. 


\section{Dritter Beweis Cohnstein's.}

"Erleichtert man die Resorption der intraperitoneal infundirten Flüssigkeit dadurch, dass man z. B. durch Massiren des Leibes den intraperitonäalen Druck steigert oder indem man durch Hochbinden der Hinterbeine die zu resorbirende Flüssigkeit dem Zwerchfelle nähert, so steigt die aus dem Duct. thoracicus ausfliessende Lymphmenge beträchtlich."

Dass Massiren des Bauches und Hochhalten des Hinterkörpers die Lymphmenge anschwellen lässt, ist ganz richtig, dass diese Steigerung der Stromgeschwindigkeit aber durch Beschleunigung der Resorption am Zwerchfell zu Stande komme, ist eine unbegrïndete Deutung. Hat Cohnstein denn niemals bei Thieren mit leerem Peritonealsacke die Lymphmenge durch Massiren des Bauches steigen sehen? Das ist doch eine allbekannte und jeden Augenblick festzustellende Thatsache. Ebenso sieht man leicht ohne Anwesenheit von Flüssigkeit in der Bauchböhle beim Hochbinden der Beine die Lymphe sich beschleunigen, z. B. in einem meiner Versuche

Lymphmenge in $10^{\circ}$

bei horizontaler Lage des Hundes $2,4 \mathrm{ccm}$

beim Hochbinden der Hinterbeine 3,3 , ",

bei horizontaler Lage. . . . . 2,4 ,

\section{Vierter Beweis Cohnstein's.}

„Die Menge der aus dem Duct. thoracicus fliessenden Lymphe muss, wenn die Resorption dureh die Lymphbahnen geschieht, während der Resorptionszeit zunehmen. Bei einem aufgebundenen Hunde nimmt nun während des Versuches die Lymphmenge mit der Zeit mehr. und mehr ab. Wenn wir also nach einer intraperitonealen Infusion (vermeintlich) isotonischer Kochsalzlösung die Lymphmenge constant bleiben oder gar - wenn aucb nur in geringem Grade - zunehmen sehen, so spricht dies zu Gunsten meiner Anschauung. Bei dem bekanntlich sebr langsamen Fliessen der Lymphe wird es allerdings eine geraume Zeit dauern, ehe die Beschleunigung des Lymphstromes in die Erscheinung tritt. Die negativen Resultate $\mathrm{Orlow}$ 's duirften sich daber vielleicht dadureh erklären, dass in jenen Versuchen der Lymphabfluss nicht lange genug controllirt worden ist." 
Bemerkangen und Versuche betreffs der Resorption in der Bauchhöhle. 327

Auch gegen diesen Beweis habe ich eine Reihe triftiger Einwendungen.

1) Es ist durchaus nicht allgemein gültig, dass die Lymphmenge aufgebundener Hunde stetig abnimmt. Eine Abnahme kommt sehr oft an den erste $n$, in Zeiträumen von je 10-15 Min. aufgefangenen Portionen zur Beobachtung. Sie hat ihren Grund darin, dass während der Präparation des Ganges und während des Einlegens der Canüle der Abfluss der Lymphe gehemmt ist, so dass sich eine Staung in den Lymphwegen bildet. Beginnt man sofort nach dem Einlegen der Canulle mit dem Auffangen, so ist die erste Portion, mitunter noch die zweite und dritte durch die voraufgegangene Stauung vergrössert, bis diese sich allmäblich ausgeglichen hat. Ist dies geschehen, so können, wenn nicht besondere Umstände einwirken, die Lymphmengen lange Zeit annähernd gleich bleiben. $\mathrm{Zu}$ den Bedingungen, welche noch fernere langsame Abnahme herbeiführen, gehört erstens allmähliches Sinken der Innentemperatur bei dem Versuchsthiere; deshalb stehen seit langer Zeit bei unsern Versuchen die Hunde stets über einem Wasserbade, dessen Dämpfe durch breite Schlitze in dem Brette, auf welches sie gebunden sind, Zugang zu dem Körper haben, der überdies mit einer Decke umhüllt ist. Weiterhin kann zweitens der Lymphstrom längere Zeit stetig sinken nach voraufgegangener Curara-Narcose, die ihn in die Höhe getrieben hat. Mitunter endlich, aber keineswegs immer, sinkt der Lymphstrom auch ohne jene nachweisbaren Ursachen. Die längsten mir bekannten Beobachtungen des Lymphstromes an Hunden ruihren von $\mathrm{Zaw}$ ilsk ${ }^{1}$ ) her; die Thiere waren nicht narcotisirt. Er findet bei ihnen während der Fettverdauung, also während Darmresorption:

in Versuch I während $60^{\circ} \ldots 0,42 \mathrm{ccm}$ pro $1 \mathrm{Min}$. dann in $40^{\circ} \ldots 0,62, ", ", \quad$, $", 40^{\prime} \ldots 0,62, ", ", \quad$, dann Constanz.

* $"$ IV während $34^{\prime} \ldots 0,70 \mathrm{ccm}$ pro $1 \mathrm{Min}$. dann in $31^{\prime} \ldots 1,11, ", "$, $, \quad 43^{\prime} \ldots 0,59, ", n, y$

zuerst Steigen, dann während $25^{\prime} \ldots 1,00 \mathrm{ccm}$ pro $1 \mathrm{Min}$. darauf in $30^{\prime} \ldots 0,83$,

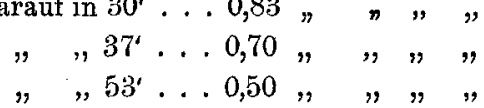

1) Zawilsky, Arbeiten aus der physiologischen Anstalt zu Leipzig. Jahrg. XI. 1876. 
in Versuch VI während $32^{\prime} \ldots 0,78 \mathrm{~cm}$ pro 1 Min. zuerst in 1 St. Constanz, darauf in $30^{\prime} \ldots 0,78, \quad ", \quad "$ dann während 2 St. wie$" \quad$ "60 $\ldots 0,42 ", ", \quad$ " der Constanz auf gerin$", 62^{\prime} \ldots 0,40, ", "$, , gerem Niveau.

$" \quad$ "VII während $45^{\prime} \ldots 0,55 \mathrm{ccm}$ pro 1 Min. darauf in $50^{\prime} \ldots 0,50, n, ", \quad$ während der ersten 145' $", 50^{\prime} \ldots 0,50, ", ", \quad$ fast völlige Constanz, $"$ "60 . $0,42, ", "$, " dann geringes Sinken.

Die obigen Zahlen lehren, dass die Basis, auf welche Cohnstein seine Beweisführung stützt, durchaus unsicher ist.

2) Es kommt bei der Frage, ob die in der Bauchhöhle resorbirten Flüssigkeitsmengen durch die Recklinghausen'schen Lymphbahnen abgeführt werden, doch ganz wesentlich darauf an, in welchem Verhältniss die während der Resorptionszeit gelieferten Lymphmengen zu den aus der Bauchböhle verschwindenden Flüssigkeitsmengen stehen. Cohnstein's Versuchsprotokolle geben keinen Anhalt zur Beantwortung dieser Frage, da die resorbirten Flüssigkeitsmengen unbekannt sind.

In meinem Versuch I wurden resorbirt $55 \mathrm{ccm}$, während der Resorptionszeit gewonnen $30,75 \mathrm{~cm}$ Lymphe.

In meinem Versuch II wurden resorbirt $104 \mathrm{ccm}$, während der Resorptionszeit gewonnen $31 \mathrm{ccm}$ Lymphe.

In meinem Versuch III wurden resorbirt $80 \mathrm{ccm}$, wälrend der Resorptionszeit gewonnen $42 \mathrm{ecm}$ Lymphe.

Die aus der Bauchhöhle verschwindenden Flüssigkeitsmengen sind doppelt so gross (III) bis mehr als dreimal so gross (II), wie die gesammte während der Resorptionszeit ausfliessende Lymphe. Nun ist aber, was aus dem Duct. thoracicus fliesst, doch nicht reines Salzwasser. Der Lymphe kann vielmehr, wie das geringe Sinken ihres Procentgehaltes lehrt, im besten Falle nur sehr wenig Kochsalzlösung beigemischt sein. Das lehren Cohnstein's eigne Zahlen. In seinem Protocoll No. III sinkt während $1 \frac{3}{4}$ Std. der Gehalt der Lymphe, während $0,6 \%$ ige Kochsalzlösung anfgesogen wird, von $5,73 \%$ auf $5,42 \%$, also um $0,31 \%$. Sollen $100 \mathrm{~cm}$ Lymphe von 5,7 Procentgehalt auf 5,4 Gehalt gebracht werden, so genügt der Zusatz von noch nicht $6 \mathrm{~cm}$ Wasser, also der Zusatz etwa $1 / 16$ des Volumens, - wobei ich als Verdunnungsflüssigkeit statt $0,6 \%$ Kochsalalösung reines Wasser annehme. Der Lymphe am Schluss der Resorptionszeit wird also $1 / 16$ ihres Volums an Wasser zugeflossen sein, wenn wirklich die Leitung: Pauchböhle - Zwerchfell - Duct. thoracicus besteht. 
In Cohnste in's Versuch, welcher die Concentrationsabnahme der Lymphe darthut, sind wie bemerkt weder die resorbirten Flüssigkeitsmengen, noch die gewonnenen Lymphmengen angegeben. Ich will deshalb an meinen Versuchszahlen prüfen, ob der von Cohnste in gewonnene Werth für die Verdünnung der Lymphe zu dem Schlusse berechtigt, den er aus denselben gezogen.

In meinen Versuchen (s. oben I-III) wurden während der Versuchsdauer $30-42 \mathrm{ccm}$ Lymphe gewonnen. Um deren Trockengehalt von dem Cohnstein'sehen Werthe 5,73\% auf $5,42 \%$ zu bringen, würden $2-21 / 2$ ecm Wasser nöthig sein. Aus der Bauchhöhle waren aber $55-104 \mathrm{ccm}$ Flüssigkeit verschwunden. Es müssten also 53-102 ccm Flüssigkeit unterwegs stecken geblieben sein, im Centrum tendineum des Zwerchfells und den von diesem zum Duct. thoracicus führenden Lymphgefässen, was natürlich eine absolute Unmöglichkeit ist. Ich habe nie eine merkliche Spur von Oedem gesehen. Der Schluss, welchen Cohnstein aus der von ihm beobachteten geringen Concentrationsabnahme zog, ist vollständig unhaltbar, vollends wenn man noch hinzunimmt den

\section{Fünften Beweis Cohnstein's.}

„Die Concentration der Lymphe nimmt nach intraperitonealer Infusion isotonischer Kochsalzlösung $a b .{ }^{6}$

Die hierher gehörigen Thatsachen sind zum Theil schon in dem vorigen Abschnitte besprochen. In der Mehrzahl der Fälle findet eine geringgradige Steigerung des Wassergehaltes statt, obschon es, wie ich an einem mir vorliegenden Falle sehe, Ausnahmen giebt. Die Abnahme des Gehaltes an festen Bestandtheilen beträgt in Cobnstein's Versuch 0,3\% (Anfang 5,73\%, Ende $5,42 \%$ ). Es ist also der Lymphe von irgend woher Wasser in geringer Menge zugeflossen. Das, aber auch nicht mehr, folgt aus Cohnstein's Versuch; er sagt nicht das Mindeste aus über die Quelle, aus welcher das Wasser stammt.

Wenn ich nun einem Hunde so viel isotonisehe Kochsalzlösung, als in 2-3 St. aus der Bauchhöhle verschwindet, in dẹr gleichen Zeit unmittelbar in eine Vene einfliessen lasse, findet eine ganz ähnliche Verdünung der Lymphe statt, wie in Cohnste in's Versuch. Ein Hund z. B. von 10 Kilo erhielt in $2 \frac{1}{4}$ St. $100 \mathrm{ccm}$ Kachsalzlösung von $1 \%$ in die $V$. jugularis. Der Trockengehalt der Lymphe sank von $6,18 \%$ auf $5,68 \%$, also um $0,5 \%$, sogar noch etwas stärker, als in dem Cohnstein'schen Beispiele. 
Von den fünf Beweisen, welche Cohnstein dafür geben wollte, dass isotonische Kochsalzlösungen aus der Bauchhöhle nicht durch die Bluteapillaren, sondern auf den Lymphwegen $\mathrm{Reck}$ li ng h a u s e $\mathrm{n}$ 's abgeführt werden, bleibt also Nichts übrig.

I. Das Blut sollte sich nicht verdiunnen. Aber erstens musste es sich bei $\mathrm{C}$ ohnstein's Versuch nach seiner eigenen Anschauung von der Resorption verdünnen, denn er füllte die Bauchböhle nicht mit isotonischer Kochsalzlösung an, sondern mit hypisotonischer, welche nach seiner Ansicht in die Capillaren durch Osmose uibergeht. Trotzdem fand er den Trockenrïckstand des Gesammtblutes constant, während ich ein geringes Sinken des Trockenrïckstandes im Serum feststellte, sowohl bei Resorption von $0,6 \%$, als von $1 \%$ Kochsalzlösung. Das Sinken ist nicht stärker, als wenn man eine der resorbirten gleiche Menge 1\% Kochsalzlösung in der gleichen Zeit direct in das Blut einfliessen lässt.

II. Cohnstein erwartet von der Resorption durch die Blutcapillaren eine wesentliche Zunahme der Harnsecretion; sie trat nicht ein. Aber sie tritt bei directer Infusion in das Blut, gleich langsames Tempo voransgesetzt, ebenfalls nicht ein.

III. Cohnstein leitet einen Beweis für die Resorption durch die Lymphbahnen von der den Lymphstrom steigernden Einwirkung ab, welche Massage des Bauches oder Hochbinden des Hinterkörpers hat. Beides gilt auch für Hunde, die nicht in peritonealer Resorption begriffen sind.

IV. Cohn ste in weist darauf hin, dass während der Gesammtdauer der Resorption der Lymphstrom nicht sinke, was er für eine relative Beschleunigung hält. Aber erstens steht der Zuwachs an Lymphe, wenn er ïberhaupt stattfindet, in keinem rationalen Verhältniss zu der Menge der in der Bauchböble resorbirten Flüssigkeit und zweitens findet ein solcher geringer Zuwachs auch bei directer Infusion von Kochsalzlösung in das Blut statt, wenn den resorbirten gleiche Mengen in gleicher Zeit infundirt werden.

V. Aehnliches gilt von der geringgradigen Verdünnung der Lymphe.

Ich bin also auf Grund der Versuche von O rlow und meiner eigenen Erfahrungen nach wie vor der Ueberzeugung, dass die wesentlichen Resorptionswege der Peritonealhöhle in den Blutcapillaren gegeben sind -, unbeschadet der auch von Orlow 
durchaus nicht bestrittenen Möglichkeit, dass die R e ckling $\mathrm{h}$ a us e n 'schen Lymphbahnen dem Brustgange unmittelbar eine geringe Menge von Flüssigkeit zufübren.

$\mathrm{Zu}$ der gleichen Ansicht über die Wege der Resorption ist H a m burger gelangt. Er stimmt mit mir auch darin überein, dass Osmose nicht die Triebkraft bei der Resorption isotonischer Flïssigkeiten sein kann. Es muss sich vielmehr um Triebkräfte handeln, welche in den Wandungen der Bauchhöhle ihren Ursprung nehmen. So weit gehen $\mathrm{Ha} \mathrm{mburger}$ und ich zusammen. Von hier ab scheiden sich unsere Wege. Meiner Ansicht nach sind jene Triebkräfte gebunden an den Lebenszustand der histologischen Constituentien der Serosa. Dem gegenüber fand $\mathrm{Ha} \mathrm{mb} \mathrm{u} \mathrm{rg} \mathrm{e} \mathrm{r}$ die verbluiffende Thatsache, dass isotonische, selbst hyperisotonische Flüssigkeiten auch beim todten Thiere, selbst noch 24 St. nach dem Tode, aus der Bauchhöhle verschwinden. Die Thatsache habe ich zu meinem nicht geringen Erstaunen bestätigt gefunden. Dennoch verlaufen im lebenden und im todten Thiere die Dinge von Grund aus verschieden, trotz aller äusseren Aehnlichkeit. Die sogenannte Rose von Jericho (Anastatica hierochuntica) entfaltet sich, wenn man ihren Stempel in Wasser steckt, durch Imbibition. Die angeschnittene Rebe blutet im Frühjahre, weil die Zellen der Wurzel durch von ihnen entwickelte Druckkräfte Wasser in die Höhe treiben. Aeussere Aehnlichkeit und innere Gleichheit sind verschiedene Dinge. Doch davon bei anderer Gelegenheit Weiteres.

\section{Nachschrift.}

Das Manuskript des obigen Aufsatzes war bereits mehrere Tage an die Redaction dieses Archivs abgesandt, als mir No. 16 des Centralblattes für Physiologie durch meine Buchhandlung zuging (am 9. November).

In demselben ist eine Kritik der Arbeit Cohnstein's von H. J. Hamburger enthalten, welche zum Theile dieselben Punkte Cohnstein gegenüber hervorhebt, die ich besprochen habe. Da aber meine Besprechung sich auf neue Versuche stützt, auch eingängiger ist, als die Besprechung $\mathrm{Hamburger}$ 's, glaubte ich meinen Aufsatz nicht zuriickziehen zu sollen. 